\title{
Concerns on Mismatches between Environments of Selection and Production of Crop Varieties in Ethiopia
}

\author{
Gemechu Keneni
}

Holetta Agricultural Research Center, P O Box 2003, Addis Ababa, Ethiopia

E-mail:gemechukeneni@yahoo.com

\begin{abstract}
Crop production plays a significant role in the Ethiopian economy. The sub-sector's output has, however, been very low partially due to the biophysical challenges constraining productivity in smallholder farms and inadequate technological interventions. Genetic modification of crops to improve productivity is preferred to the continual manipulation of the growing environment because of cost particularly to the large majority of resource-poor farmers who cannot afford for production inputs. Consideration of varietal selection vis-à-vis actual target production environment is vital to maximizing gains from breeding efforts. The tradition across most of the breeding programs in Ethiopia is to develop varieties under optimum management despite the fact that marginal management characterizes the ultimate target production environments. Whether selection under optimum management is likely to result in better productivity gain than under the actual target production environments is a crucial issue in varietal development. This paper discusses the logical framework for breeding success and the conventional approach to varietal selection and its challenges in Ethiopia. Based on the analyses, the paper proposes that the wheel of the current variety development schemes should be redirected and made more objective and focused towards better serving the major target beneficiaries, i.e. the resource-poor farmers.
\end{abstract}

Keywords: Direct Selection; Indirect Selection; Selection Environment; Target Environment

\section{Introduction}

Agriculture is the backbone of the Ethiopian economy. The sector contributes $85 \%$ of total employment, $46 \%$ of GDP and $92 \%$ of total export earnings (Beintema and Menelik, 2003). Crop production takes the lion's share of the contribution by agriculture as a whole in terms of employment, food, industrial raw materials and export earnings. For instance, more than $95 \%$ of the export earnings were contributed from exports of different crops and crop products in 2005, disregarding plant-animal mixed products (CSA, 2006). Despite the manifold merits, however, crop productivity has been very low due partly to a two-prong, the biophysical challenges constraining productivity under the smallholder farms' conditions on the one hand and inadequate technological interventions made to curb the culprit on the other. To bridge the widening gap between the radically increasing demand and the diminishing supply of food, industrial raw materials and export commodities, technological backing of production, among others, is absolutely essential. Among the important ways of confronting this challenge, the use of modern production inputs, better agronomic practices, and introduction of improved crop cultivars into the production system stand forefront.

Even though a good level of investment has been made in research particularly after the 1990's, the inception of formal crop breeding in Ethiopia may date back to the 1940's with the establishment of higher learning institutions (Beintema and Menelik, 2003). As a result, over 400 improved varieties of different crops have been released for common production (MoARD, 2005). Nevertheless, it is hardly possible to say that most of these varieties have been readily accepted, properly utilized and boosted productivity at farm level as desired. On-station yields are usually attractive but the spillover effects in farmers' fields were often observed to be negligible (Franzel, 1992). Improved cultivars of most of the crops are not yet sufficiently put under production and more than $95 \%$ of the cultivated areas in the country are still planted with local seeds produced by the farmers themselves. For instance, out of the 10,887,953 ha of land cultivated to different crops in the 2004/2005, only 346,522 ha $(3.2 \%)$ was covered with improved seeds (CSA, 2005). The national average yields for most of the crops are low (Ethiopian Agricultural Sample Enumeration, 2002) and stagnant (Woldeyesus and Chilot, 2002) while yields of two to three folds of the respective crops have been commonly recorded from improved varieties with proper crop management and protection practices (EARO, 2000; Belay, 2004; Legesse, 2004). The situation is also similar in many other African countries (Ceccarelli, 1997).

The main reasons for less research impact in Ethiopia, among others, have often been stated as lack of proper multiplication, dissemination and utilization of improved technologies including improved seeds (Belay, 2004; Adugna et al., 2006). The weakness, or sometimes even the irrelevance, of "improved" technologies (including crop varieties) is also coming into picture, the main complaint being technology development processes including varietal generation often do not take into consideration the biophysical and the socio-economic situations of the target production systems (Franzel, 1992). The purpose of this review paper is not, by any means, to argue that past breeding efforts were ineffective and the varieties developed were irrelevant. With due 
respect to the efforts made and the achievements so far, the paper rather aims to challenge the conventional varietal development approach in Ethiopia based on some conceptual frameworks and available scientific evidence. That, I hope, would provoke critical discussion and useful dialogues among the scientific community on the need to revisit and redirect the scheme of variety development in order to make future breeding efforts in Ethiopia more objective and focused.

\section{Conceptual Frameworks and Conventional Approaches to Selection}

Progress in breeding depends on the magnitude of genetic variability among the germplasm, heritability of a given trait in a given environment and the level of selection intensity applied (Falconer, 1989; Singh, 2002). The higher the level of genetic variability, heritability and selection intensity for a given trait in a given environment, the higher will be the expected genetic gain from selection. This could be clearly revealed from the interrelationship between expected genetic gain from selection on the one hand and genetic variance, heritability and selection intensity on the other which will be discussed later in greater detail.

Environmental conditions and crop management practices interplay to determine the extent and pattern of genetic expression of different traits including yield potential. Therefore, the environment and the farming system for which breeding is undertaken, farmers' and consumers' preferences and characteristic to be modified under specific situations should be clearly defined and; accordingly, appropriate germplasm should be identified and proper breeding methods followed for a successful breeding program. The term environment in this sense refers to both natural components like climatic, edaphic and biotic (pests) factors and management and protection practices provided to crops (Annicchiarico, 2002).

The appropriateness of varieties for release in terms of performance consistency across a range of physical environments is confirmed by multi-location evaluation of varieties even if it is laborious, costly and time consuming. Hence, varieties are normally evaluated at few locations (primary breeding centers) at the initial stages when a large number of germplasm is handled. As the evaluation work is further kept on, at later stages, the number of varieties virtually gets smaller and smaller through selection while the number of locations is steadily increased over years. While planned specific breeding programs exist for potential and stress conditions in terms of physical environments like moisture and altitudinal regimes in different crops including cereals, pulses and oil crops (EARO, 2000), no such program exists for management levels despite the importance. The current conventional breeding approach in the tropics in general and in Ethiopia in particular is development of varieties under optimum management levels (favorable conditions) on experiment stations and release of the promising ones as registered varieties for inevitable production under marginal management levels (unfavorable conditions) in farmers' fields (Banziger et al., 1998; Gemechu et al., 2002). However, a number of varieties that performed better with optimal management on research stations could not consistently repeat the same performance under farmers' fields which are characteristically of sub-optimal conditions (Ceccarelli, 1989; Ceccarelli and Grando, 1996; Banziger and Edmeades, 1997; Banziger et al., 1997; Banziger and Lafitte, 1997). The existence of genotype by management interactions reported from Ethiopia (Abdissa, 1996; Kenea, 2004; Getachew and Amare, 2004; Amare et al., 2005; Balesh et al., 2005) has made doubtful whether genotypes that performed better with optimal management on research stations could consistently perform the same under farmers' fields.

\section{Why Develop Varieties Under Optimum Management?}

Breeders tend to develop varieties under optimum conditions for an ultimate use under marginal management, which prevails in the target production environments. Different possible reasons could be given why selection under optimum conditions is the most common approach.

The main reason for varietal selection under optimum management in the tropics in general and in Ethiopia in particular, could be not necessarily because it is the best approach but breeding methodologies in the tropics are generally influenced by experiences from breeding in the temperate areas (Banziger et al., 1998). The success stories from plant breeding as a science led the developed nations to technological breakthrough based not only on genetic manipulation of the crops but also on the integration of better management with improved genotypes that are responsive to such management options. The approach served best the purpose of developed nations because management levels applied on experiment stations could be afforded in farmers' fields whereas in the tropics, management levels applied on breeding stations are very different from those affordable by the farmers. The continued demand for food and the success of such efforts, in some parts of the world, as the Green Revolution, might be the main driving force for an ambitious approach to transform the whole farming system at once by adopting breeding methodologies which are successful in the developed nations without much modification. However, experiences from the Green Revolution did not repeat in a sustainable manner in most parts of Africa partially because the input level required along with the new varieties was too high for the resource-poor farmers (Singh, 2000). One should not also overlook the role, in modeling our research approach, of expatriates from the developed nations who dominated the research system during the early days in Ethiopia (Beintema and Menelik, 2003).

Another reason for selection under optimum management might be the assumption that heritability and 
expected genetic gains from selection are higher, and hence, there would be more success under favorable than under unfavorable management conditions (Simmonds, 1991; Banziger and Edmeades, 1997; Singh, 2002). The importance of this concept may emanate from the assumption that superior genotypes under optimum management would also be superior under low management condition (Brennan and Byth, 1979; Rosielle and Hamblin, 1981). If this assumption was true, breeders could have efficiently evaluated cultivars under optimum management for both optimal and marginal levels and thereby save resources. It was also used to be assumed previously that farmers could afford for and decide to take up improved varieties along with recommended crop management practices as a "package" provided that the package as a whole is profitable, which was later proved, beyond doubt, to actually be unlikely (Franzel, 1992; Getaw and Girma, 2004).

\section{Challenges of the Conventional Approach to Selection}

Under farmers' conditions, the full genetic yield potential of crops may be rarely attained because of environmental limitations imposed not only by the natural environment but also by the sub-optimal management. There is no purpose in breeding pest-resistant genotypes in pest-free environments, drought-resistant genotypes in drought-free environments or frost-resistant genotypes in frost-free environments. Similarly, varieties selected under high yield potential on research stations should not be assumed appropriate under farmers' fields where very marginal management prevails (Banziger et al., 1998). Therefore, selection under optimum management conditions may not be the best approach for Ethiopia to boost productivity of all crops under marginal management conditions in farmers' fields.

Many studies claimed to have proved the concept that cultivars selected under favorable environments also suit to the unfavorable ones does not have sufficient scientific background (Ceccarelli, 1989; Ceccarelli and Grando, 1996; Banziger and Edmeades, 1997; Banziger et al., 1997; Banziger and Lafitte, 1997). Many of such varieties developed under potential conditions failed to succeed under marginal conditions (Ceccarelli, 1989; Reijntjes et al., 1992; Ceccarelli and Grando, 1996) because it is practically impossible to collect together genes responsible for superior performance in all environments into a single genotype (Annicchiarico, 2002). The reason for the poor performance of most of the modern cultivars developed this way in the tropics is widely attributed to the fact that they require management and input levels which most of the growers could not afford (Farrington and Martin, 1988; Franzel, 1992).

Some studies in Ethiopia report the existence of significant genotype by management interaction in a number of crops including sweet potato (Abdissa, 1996), chickpea (Kenea, 2004), faba bean (Getachew and Amare, 2004), field pea (Amare et al., 2005) and tef
(Balesh et al., 2005). When the genotype by management interaction is a crossover type, it means that the two management levels are distinctly different and they do not represent one another in terms of variety generation (van Oosterom et al., 1993). It is not only the nature of the test genotypes but also the degree of similarity between selection and target production environments that influences the magnitude of genotype by management interaction (Cleveland, 2001). In cases of high genotype by management interaction to the extent that it causes rank order changes among the genotypes, there is no scientific base to select varieties under one management level to indirectly improve productivity under another (Ceccarelli and Grando, 1996).

\section{The Concept of Direct vis-à-vis Indirect Selection}

The concept of direct and indirect selection was suggested by Falconer (1960) and later used in several investigations related to the determination of optimum selection environments (Ceccarelli, 1989; Ceccarelli and Grando, 1996; Banziger and Edmeades, 1997; Banziger et al., 1997; Banziger and Lafitte, 1997). Accordingly, direct selection may refer to a kind of selection made directly under the target production environment or under simulated condition as the target environment. Indirect selection, conversely, refers to selection made under distinctly different environment from the actual target production environment but still to improve productivity under the latter; for example, selection under potential environment to improve productivity under marginal conditions.

Methods have been designed (Falconer, 1989) to determine the efficiency of selection under favorable environments like research stations for improving performance under unfavorable target environments like farmers' fields. The procedure assumes a character measured in two different environments not as one but as two characters with genetic correlation between them since the physiological mechanisms and the genes required for high performance may be different. If the genetic correlation between them is high, then performances in two different environments represent nearly the same character, determined nearly by the same set of genes. If it is low, however, the characters are likely to differ to a great extent, and high performance requires a different set of genes.

Given genetic variances in a target environment $\left(\sigma^{2}\right.$ $(T E)$, heritability in selection $\left(h_{(S E)}^{2}\right)$ and target $\left(h_{(T E)}^{2}\right)$ environments, selection intensity $(\delta)$ and genetic correlation between the performances under the selection and target environments $\left(r_{g}\right)$, the expected response to direct selection (DR) in a target environment and the expected response to indirect selection in a selection environment (IR) can be determined as (Falconer, 1989):

$$
\begin{aligned}
& D R=\delta . \sigma_{g(T E)} \cdot h_{(T E)} \\
& I R=\delta . r_{g} \cdot \sigma_{g(T E)} \cdot h_{(S E)}
\end{aligned}
$$


The relative efficiency (RE) of indirect selection under selection environment as compared to direct selection under target environment (DR) is calculated as:

$$
\mathrm{RE}=r_{g} \cdot h_{(S E)} h_{(T E} \text { or IR/DR }
$$

A value of 1.0 indicates that indirect selection under the selection environment to improve productivity under the target environment is predicted to be equally efficient as selection under the target environment itself. Similarly, a value of less than 1.0 indicates more efficiency of direct selection and a value of more than 1.0 indicates more efficiency of indirect selection (Banziger and Edmeades, 1997; Banziger et al., 1997; Banziger and Lafitte, 1997). A simplified schematic presentation of the appropriateness of direct or indirect selection under different levels of genotype by management interactions is presented in Figure 1.

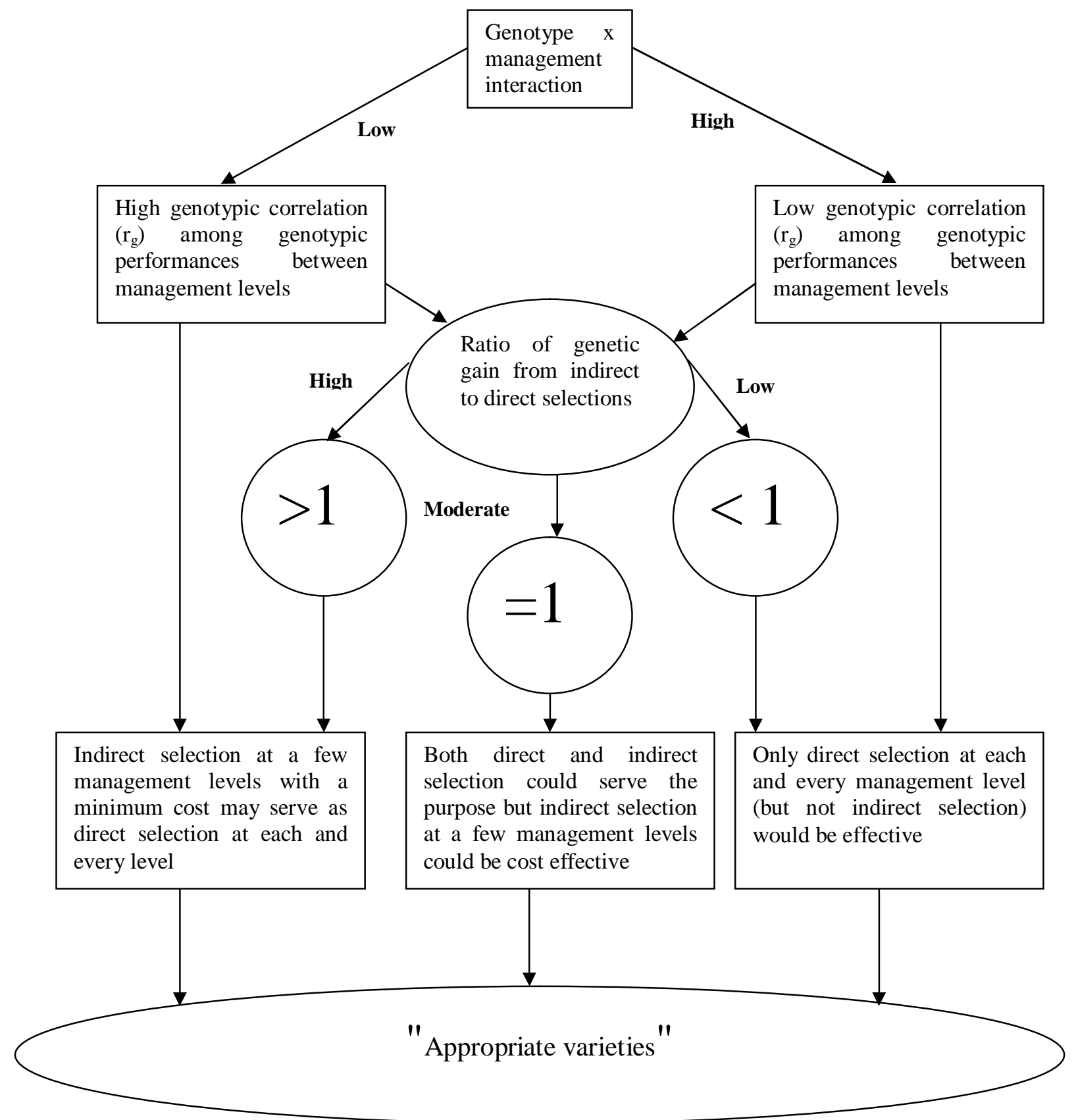

Figure 1. Schematic presentation of appropriate uses of direct or indirect selection where low or high genotype by management interaction prevail 


\section{Where Do We Stand?}

In countries like Ethiopia where resource-poor farmers dominate and crops are produced under marginal situations, it is not feasible to develop and universally utilize resource-demanding varieties. Although high inputs could boost productivity, high-input technologies may not be widely adopted by resource-poor farmers because such practices must be repeated each season and are hence expensive.

A variety may show outstanding performance at a research station under optimal management conditions and inferior performance under the target marginal management conditions prevailing in the farmers' fields. The specificities for management requirement among crop genotypes suggests that either varieties must be selected under representative management conditions or under management levels with which they are going to be extended. The success stories from varietal introductions during the Green Revolution were mainly based on the abilities of countries to manipulate their growing environments in such a way that the varietal requirements could be satisfied. On the other hand, the failure of technology introductions like the pure breeds of European livestock, particularly dairy cows, under small-scale production in Africa was at least partially related to inability of the farmers to provide the required management level (Tesfaye, 1988).

Table 1. Comparison of selection and target production environments for different crops in Ethiopia

\begin{tabular}{|c|c|c|c|}
\hline Crops & $\begin{array}{l}\text { Parameter } \\
\text { of comparison }\end{array}$ & Selection environment & Target environment \\
\hline All crops & $\begin{array}{l}\text { Farm implement for } \\
\text { land preparation }\end{array}$ & $\begin{array}{l}\text { Tractor mounted (mold board, disc plow, } \\
\text { etc.) }\end{array}$ & $\begin{array}{l}\text { Simple local implements (maresha*, } \\
\text { hoe, etc.) }\end{array}$ \\
\hline \multirow[t]{5}{*}{ Pulses } & Plowing frequency & $\begin{array}{l}2-3 \text { plowings with local plow or one disc } \\
\text { plowing followed by two disc-harrowing }\end{array}$ & $\begin{array}{l}\text { A single plowing plus another } \\
\text { plowing to cover the seed in most of } \\
\text { the cases }\end{array}$ \\
\hline & Fertilizer & $\begin{array}{l}\text { Blanket application of } 18-48 \mathrm{~kg} \mathrm{~N}-\mathrm{P}_{2} \mathrm{O}_{5} \\
\mathrm{ha}^{-1} \text { at most of the locations and no } \\
\text { fertilizer is added in some others }\end{array}$ & Not added in most of the cases \\
\hline & Weeding & $\begin{array}{l}\text { Twice hand weeding or sometimes weed } \\
\text { free particularly in breeding blocks }\end{array}$ & $\begin{array}{l}\text { Not weeded in most of the cases or } \\
\text { often late weeded once }\end{array}$ \\
\hline & Cropping system & Sole cropping & $\begin{array}{l}\text { Sole or mixed culture of faba bean } \\
\text { and field pea }\end{array}$ \\
\hline & Field selection & $\begin{array}{l}\text { Mostly potential land for full genetic } \\
\text { expression }\end{array}$ & $\begin{array}{l}\text { Mostly marginal land for fertility } \\
\text { restoration }\end{array}$ \\
\hline \multirow[t]{4}{*}{ Cereals } & Plowing frequency & $\begin{array}{l}\text { May be less frequent than in the target } \\
\text { production environments but with tractors }\end{array}$ & $\begin{array}{l}\text { 3-7 times depending on the type of } \\
\text { crop }\end{array}$ \\
\hline & Fertilizer & $\begin{array}{l}\text { Agronomic recommendation of each of } \mathrm{N} \\
\text { and } \mathrm{P}_{2} \mathrm{O}_{5} \text { or sometimes even more } \\
\text { particularly in breeding blocks }\end{array}$ & $\begin{array}{l}\text { Below the blanket recommendation } \\
\text { in most of the cases, tendency to use } \\
\text { more } \mathrm{P}_{2} \mathrm{O}_{5} \text { than } \mathrm{N}\end{array}$ \\
\hline & Weeding & $\begin{array}{l}\text { Agronomic recommendation or even weed } \\
\text { free in breeding blocks }\end{array}$ & $\begin{array}{l}\text { Weeded mostly later than } \\
\text { recommended or use herbicide or } \\
\text { hand weeding supplemented with } \\
\text { shilshalo** }\end{array}$ \\
\hline & Cropping system & Selection under sole cultures & $\begin{array}{l}\text { Sole culture dominates but mixed } \\
\text { culture is still important }\end{array}$ \\
\hline \multirow[t]{4}{*}{ Oil crops } & Plowing frequency & $\begin{array}{l}\text { May be as frequent as in the target } \\
\text { production environment but with tractors }\end{array}$ & $\begin{array}{l}0-2 \text { times depending on the type of } \\
\text { crop }\end{array}$ \\
\hline & Fertilizer & $\begin{array}{l}\text { Agronomic recommendation of each of } \mathrm{N} \\
\text { and } \mathrm{P}_{2} \mathrm{O}_{5}\end{array}$ & Not added in most of the cases \\
\hline & Weeding & $\begin{array}{l}\text { Agronomic recommendation of each crops } \\
\text { or even weed free in breeding blocks }\end{array}$ & Not weeded in most of the cases \\
\hline & Cropping system & Selection under sole cultures & $\begin{array}{l}\text { Both sole and mixed cultures are } \\
\text { important }\end{array}$ \\
\hline
\end{tabular}

Source: Personal observations, and extracted from Amare and Adamu (1994), Hauilu et al. (1994), Rezene (1994) and Hailu et al. (1996)

*Maresha is a small iron point at the tip of a wooden plow used to crumble the soil 15-20 cm deep.

** Shilshalo is inter-row cultivation with a local plow for weed control and thinning particularly in maize and sorghum. 
As noted, the crop management levels in varietal selection and target production environments in Ethiopia are very different (Table 1). Reasons for larger genotype by environment interaction include difference in varietal response and environmental distinctness in terms of biophysical and management factors (Annicchiarico, 2002). From the apparent differences between selection and target production environments presented in Table 1, one can easily expect system incompatibility between the two as even a single or a few components of a management package with a few genotypes might result in a significant genotype by management interaction (Abdissa, 1996; Kenea, 2004; Getachew and Amare, 2004; Amare Ghizaw et al., 2005; Balesh et al., 2005). As varieties developed for resourceful conditions may not be flexibly suited under resources-poor situations, so do those that are developed under researcher managed sole cultures for production under a more complicated target mixed cultures (Smith, 1986).

Among the key management inputs, for instance, commercial fertilizers are the most important but most expensive in Ethiopia. The rate of fertilizer applied by Ethiopian farmers is very low compared to the rate used at research stations (Table 1). The main problem is not only the limited supply but also the higher price of the limited amounts availed to farmers. Unfortunately, the cost of fertilizer may continue to rise to the level farmers in developing countries in general may not afford to purchase (FAO, 1984). It is likely that fertilizer prices will rather rise in the future due to the dwindling oil reserves (Beem and Smith, 1997). Organic sources like farmyard manure are also limited (Quinones et al, 1997). Therefore, production is mostly based on the traditional approach although farmers realize the importance of using inputs. With the rising price of inputs, therefore, the breeding of genotypes that efficiently utilize resources, i.e. genotypes that are able to mobilize the limiting resources in greater amounts and yield better than a standard cultivar (Graham, 1988; Bowen and Zapata, 1991), instead of genotypes responsive to management, may be a dependable approach to address the problem of the majority of the resource-poor farmers in Ethiopia.

Apart from some variety evaluations made both under fertilized and unfertilized conditions during the 1980's and a number of genotype by management interaction studies conducted on different crops, systematic efforts made to establish optimum selection environments in Ethiopia are very limited. Among a few systematic studies include on faba bean to determine if selection of good genotypes under drained condition is also efficient for identification of appropriate genotypes for the undrained target environments on waterlogged Vertisols (Gemechu et al., 2001). Another similar case was a study done on barley to determine the effectiveness of selection under high soil nitrogen level for low nitrogen target environments (Woldeyesus et al., 2002). Both studies clearly revealed the relative advantage of direct selection under the target environments than if indirect selection were done under more favorable environments particularly as the level of marginality increases, although indirect selection as well may be useful in some cases to identify better genotypes. These indicate that if the breeders' selection environment does not properly represent the actual target production conditions, selection gains under the former may be of little or no help to improve yield under the latter. Verifying a few "finished" candidate varieties under the target condition at the final stage of variety evaluation can also not make up for the useful genetic variation that might have already been lost when large number of genotypes that would have been suited under marginal conditions were discarded on the station under breeders' own condition (Banziger et al., 1998).

At times in the 1980's, it was almost a general trend to evaluate varieties under fertilized and unfertilized conditions. Analysis of the data showed existence of crossover types of genotype by soil fertility level interactions causing changes in rank orders among the performances of the genotypes of different crops including cereals, pulses and oil crops in most of the cases (Fig. 2). This clearly shows that the fertilized and the unfertilized soil environments were distinctly different and the genotypes responded differently to the different soil fertility levels. This could also be further confirmed from weak correlations between varietal performances under the two fertility levels in most of the cases (data not shown). Such weak associations indicate that selection of better performing genotypes for grain yield under fertilized could not identify better performing genotypes for unfertilized conditions (Banziger et al., 1997; Banziger and Edmeades, 1997). The production of varieties developed for fertilized condition might not, therefore, be recommendable under unfertilized condition and there may be a need to specifically bred varieties for the latter.

\section{Future Considerations}

In order to boost the productivity of crops in this country to the desired level, among other factors, the demand for varieties appropriate under farmer circumstances need to be satisfied. Therefore, the mismatch between selection and target production environments could be of paramount importance for future consideration. It does not mean that the existence of any level of differences between the selection and the target production environments necessarily indicate selection for one condition does not serve for the other. In case when relative efficiency of direct selection under one condition is proven superior over indirect selection under the other, it means that the two environments are exclusively independent. In such cases, we may need to separately address optimal and marginal management situations or to redirect the varietal generation process as a whole towards the vast majority of the resourcepoor farmers. To the less favored resource-poor farmers in Ethiopia, there is no doubt that a variety giving reasonably good yield under their own circumstances is more important than a high-yielding variety based on high investment for inputs. 

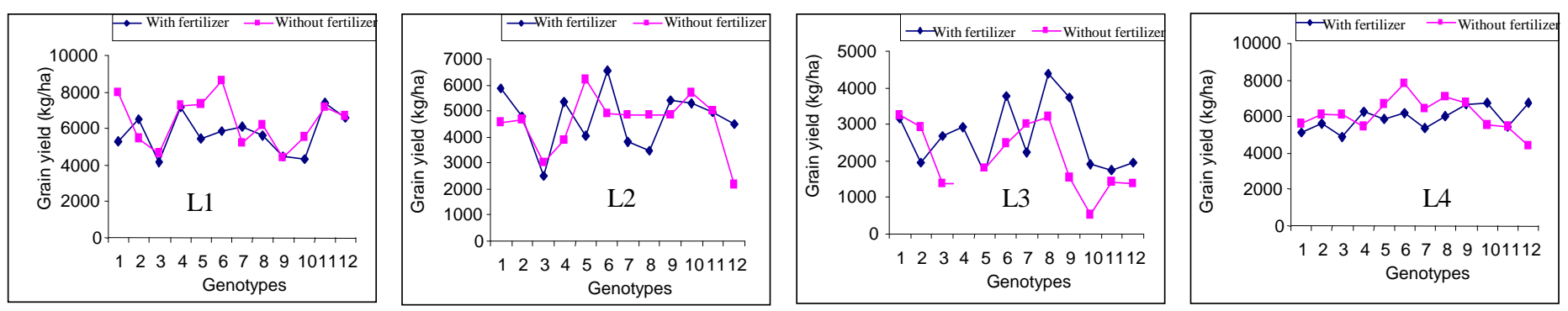

(A) Maize (composites)
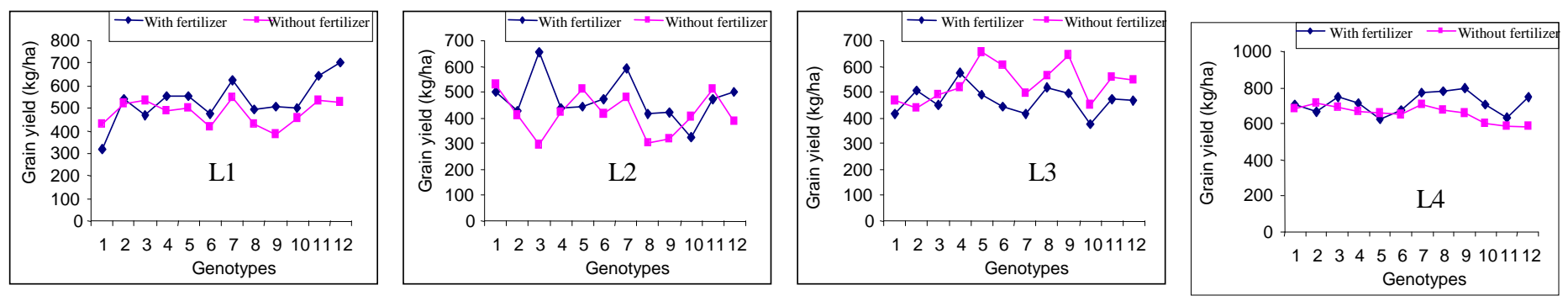

(B) Niger seed
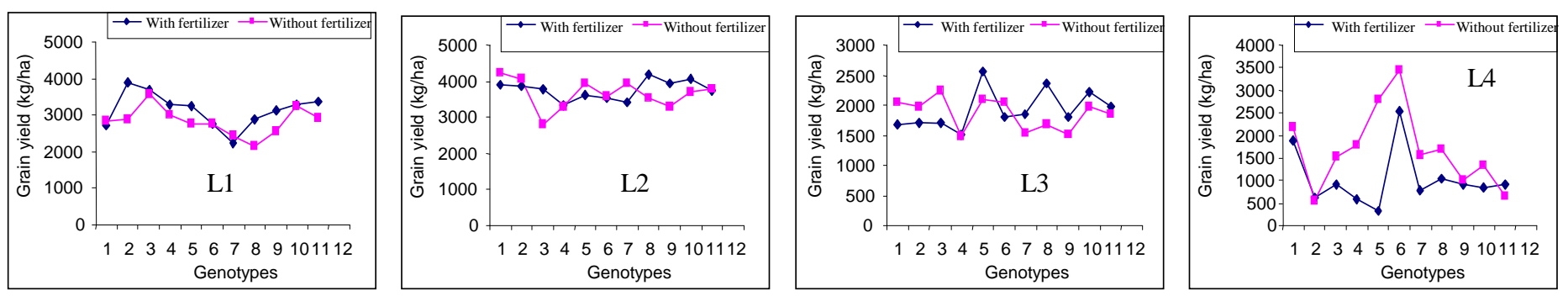

(C) Faba bean
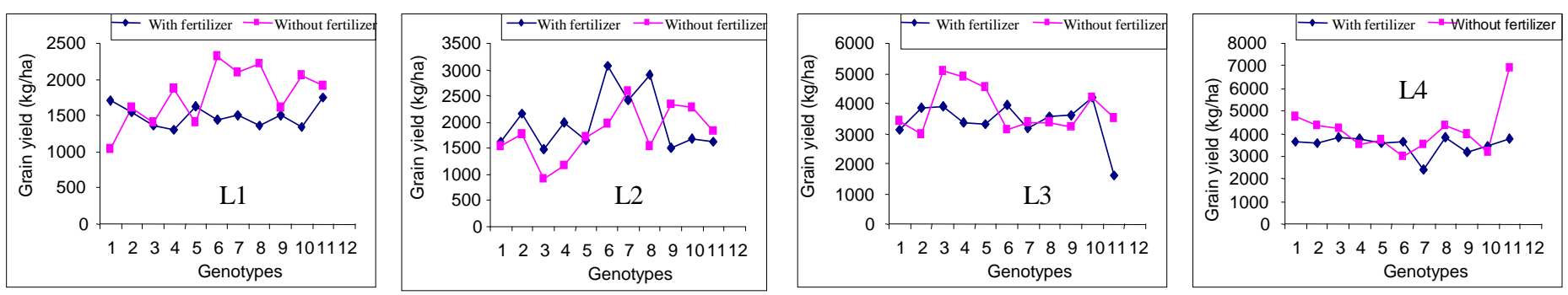

(D) Field pea

Figure 2. Grain yield performances of maize, Niger seed, taba bean and field pea genotypes across four locations each (L1-L4) under fertilized and unfertilized conditions showing the existence of cross-over type genotype by management interaction (data taken from IAR (1986) and re-manipulated by the author) 
Depending on the practical situations existing in a given farming system, several assumptions could be thought of in the process of generation of appropriate varieties suitable under the target condition in Ethiopia. The first assumption is that farmers would afford to take up the whole production packages along with the varieties. The ultimate goal of this option is yield potential based on the full exploitation of productivity improvements from genotype, management and any positive synergic interaction between them. However, the option did not widely apply for an obvious reason that the majority of the resource-poor farmers may not afford the cost of production inputs. With the rising price of inputs, therefore, the breeding of productive genotypes, which are suitable under low management levels and simulated farmers' circumstances, could prove one of the dependable approaches to address the problem of the majority of the resource-poor farmers in Ethiopia. Research and extension experiences over the last couple of decades in Ethiopia also showed that this assumption did not work and technology adoption may rather follow a step-by-step pattern where components of the same package may be adopted separately at different times (Franzel, 1992).

The second option is that breeders must recognize farmers' unique situations and develop varieties based on their socio-economic needs as ignoring farmers' practical situations may end up in shelving the varieties without any significant adoption to bring-up impact on agricultural development. Contrary to the first option, the ultimate goal here is not yield potential but resistance to biotic and abiotic stresses in farmers' fields including adaptation to marginal management. With this assumption breeding efforts should build on farmers' practices to complement them and not to substitute them. The process in which cultivars are adapted to fit the prevailing environment is encouraged instead of the environment being altered to fit the cultivars (Coffman and Smith, 1991; Wallace and Yan, 1998). This option is normally more appropriate under very marginal production conditions where price ratios between external inputs and farm outputs do not allow the use of large quantities of purchased inputs (de Boef et al., 1996). Landraces have considerable breeding values under these kinds of situations as they contain valuable adaptive genes to different circumstances (Ceccarelli, 1994; Bunder et al., 1996; Chahal and Gosal, 2002). Once appropriate varieties are made available this way their adoption may involve no additional expense apart from the initial seed cost, and the existing cropping system and soil and water management practices may not be affected (Buddenhagen and Richards, 1988). Experience also shows that seed based technologies are easier to transfer to farmers than more complex knowledge based agronomic practices (Edmeades et al., 1998). However, this approach has also its own limitations. We should not anticipate dramatic results from breeding efforts in marginal environments but only small gradual changes should be expected (Buddenhagen and Richards, 1988). The development of suitable genotypes to marginal management situations may not provide the required productivity levels as lower genetic gains expected from selection under such circumstances (Rosielle and Hamblin, 1981; Buddenhagen and Richards, 1988; Singh, 2002) may limit yield improvements, result in further depletion of soil nutrients and thereby put at risk the national desire to double or triple productivity in order to feed the increasing population (Woldeyesus and Chilot, 2002).

Thirdly, there could be a compromise between researchers and farmers in such a way that researchers may consider only those pertinent socio-economic backgrounds of the farmers while at the same time farmers also try to take up affordable packages. This option assumes that certain level of productivity could be achieved from a compromise between management levels and from appropriate genotypes that are capable of efficiently exploiting the limited management levels that could be affordably provided by the farmers. Some authors advise that the use of modest level of inputs or intermediate environment is feasible for small-scale farmers over both high and low yielding environments (Allen et al., 1978; Franzel, 1992). This approach seems to be socially acceptable but it does not concur with the concept of "agronomic optimum" advocated by agronomists. If we make this our choice, it is biologically true that we cannot achieve the maximum desired level of development we could have liked to see but it could at least be considered, compared to the second option, as a matter of "choosing the lesser evil when we are between two evils".

Fourthly, testing of varieties under both optimal and marginal or sub-optimal conditions could be one of the stable options to create alternative varieties that suit both conditions but the cost of germplasm evaluation would obviously be greatly increased.

\section{Conclusion}

It is obvious that if a variety developed for better agronomic performance by breeders is ultimately unacceptable to farmers for some reasons and is not adopted, all the resources invested to the development of that variety will be lost. I think that we do not have to oscillate among many choices but only two. The first is that the actual situation on the ground must be properly assessed, defined and appropriate varieties suitable under the real-life situations of our farmers must be developed, made available, accepted and properly utilized in production. Another choice, may be a more sound one, is that farmers must be enabled with policy supports (in terms of access to education, credit, input supply, markets and extension services, etc) to alter their growing environments through the application of improved inputs and agronomic practices that suit newly developed cultivars. Whatsoever the future may come with, we need to critically reassess and redirect the wheel of the scheme of variety development in order to make our future breeding efforts more objective and focused. To this effect, scientists and research institutions may be responsible at the technical level to decide on the 
appropriate models to be followed in the future based on the prevailing circumstances or the national vision as the case may be. Above all, fundamental changes in this aspect, apart from research, must be expected from enabling policy and strategy directives that envisaged transforming crop production from a means of survival to a profitable business.

\section{Acknowledgements}

I thank Dr. M. Banziger and Dr. G.O. Edmeades of CIMMYT who, for the first time, introduced me to the concept of selection and target environments at a training workshop on breeding maize for drought, low $\mathrm{N}$, striga and stem-borer resistance in Arusha, Tanzania, in 1998. I am also grateful to Dr. Nigusie Alemayehu, Dr Dereje Gorfu, Mr. Amare Molla and Mr. Mussa Jarso of the Ethiopian Institute of Agricultural Research for constructive comments on the first draft of this article.

\section{References}

Abdissa, G. 1996. The potential contribution of sweet potato to food and income security of farmers: On farm research outputs from Bako area. In: Sebil. Proceedings of the $7^{\text {th }}$ Annual Conference of the Crop Science Society of Ethiopia. 27-28 April 1995, Addis Ababa, Ethiopia. pp. 66-77.

Adugna, W., Gemechu, K., Getachew, A., Gebremedhin, W. 2006. Supporting alternative seed delivery systems in AHI-Galessa watershed site, Ethiopia. In: Amede.T., German, L., Opondo, C., Rao, S. and Stroud, A. (eds.). Integrated Natural Resource Management in Practice: Enabling Communities to Improve Mountain Livelihoods and Landscapes. Proceedings of a Conference held on October 12-15, 2004 at ICRAF Headquarters, Nairobi, Kenya, Kampala, Uganda: African Highland Initiative. pp. 240-248.

Amare, G., Du Freez, C.C. and Taye, B. 2005. Effect of phosphorus fertilizer on grain yield of field pea (Pisum sativum L.) cultivars. Ethiopian Journal of Natural Resources 7 (1): 1-21.

Amare, G. and Adamu, M. 1994. Faba bean and field pea agronomy research. In: Asfaw, T., Geletu, B., Saxena, M.C.and Solh, M.B. (eds.). Coolseason Food Legumes of Ethiopia. Proceeding of the First National Cool-Season Food Legumes Review Conference, 16-20 December 1993, Addis Ababa, Ethiopia. ICARDA/IAR. ICARDA, Syria. pp. 199-227

Allen, F. L., Comstock, R.E. and Rasmuddon, D.C. 1978. Optimal environments for yield testing. Crop Science 8: 747-751.

Annicchiarico, P. 2002. Genotype x Environment Interaction: Challenges and Opportunities for Plant Breeding and Cultivar Recommendation.
FAO Plant Production and Protection Paper No. 174. Food and Agriculture Organization, Rome.

Balesh, T., Bune, F. Z., Jens, A. and Bishal, S. 2005. N fertilization, soil type and cultivar effects on $\mathrm{N}$ use efficiency in tef (Eragrostis tef [Zucc.] Trotter. Nutrient Cycling in Agroecosystems 71: 203-211.

Banziger, M. and Edmeades, G.O. 1997. Predicted productivity gains from breeding maize under stressed vs. non-stressed conditions. In: Ransom, K., Palmer, A.F.E., Zambezi, B.T., Mduruma, Z.O., Waddington, S.R., Pixley, S.R. and Jewell, D.C. (eds.). Maize Productivity Gains through Research and Technology Dissemination: Proceedings of the $5^{\text {th }}$ Eastern and Southern Africa Regional Maize Conference (Arusha, Tanzania, 3-7 June 1996). CIMMYT, Addis Abeba, Ethiopia. pp. 136- 140.

Banziger, M., Betran, F.J. and Lafitte, H.R.1997. Efficiency of high-nitrogen selection environments for improving maize for lownitrogen target environments. Crop Science 37: 1103-1109.

Banziger, M., Edmeades, G.O., Beck, D. and Bellon, M. 1998. Breeding for drought and low $\mathrm{N}$ tolerance in maize. Regional Workshop for Breeders and Agronomists of ASARECA Member States, held in Arusha, Tanzania, September 1-14, 1998.

Beem, V. and Smith, M.E. 1997. Variation in nitrogen and phosphorus efficiency and root system size in temperate maize genotypes. In: Edmeades, G.O., Banzinger, M., Mickelson, H.R. and Pena-Valdivia, C.B. (eds.). Deveolping Drought and Low N-tolerant Maize. Proceedings of a Symposium, March 25-29, 1996, CIMMYT, El Batan, Mexico. Mexico D.F., CIMMYT. pp. 241-244.

Beintema, N.M. and Menelik, S. 2003. Ethiopia Agricultural Science and Technology Indicators (ASTI). ASTI Country Brief No. 9. http://www.ASTI.cgiar.org.

Belay, S. 2004. Agricultural input system and publicprivate partnership. In: Tesfahun, F. and Osman, A. (eds.). Proceedings of Food Security Conference 2003: Challenges and Prospects of Food Security in Ethiopia. August 13-15, UNCC, Addis Ababa, Ethiopia. pp. 107121.

Bowen, G.D. and Zapata, F. 1991. Efficiency in uptake and use of nitrogen and phosphorus by plants. In: Stable Isotopes in Plant Nutrition, Soil Fertility and Environmental Studies. Proceedings of an International Symposium on the Use of Isotopes in Plant Nutrition, Soil Fertility and Environmental Studies, 1-5 Oct. 1990, IAEA, Vienna. pp. 349-362. 
Brennan, P.S. and Byth, D.E. 1979. Genotype and environmental interactions for wheat yields and selection for widely adapted wheat genotypes. Australian Journal of Agricultural Research 30: 221-232.

Buddenhagen, I.W. and Richards, R.A. 1988. Breeding cool season food legumes for improved performance in stress environments. In: Summerfield, R.J. (ed.). World Crops: Cool Season Food Legumes. Kluwer Academic Publishers, the Netherlands. pp. 81-95.

Bunder, J., Loeber, A., Broers, J.E.W. and Havertkort, B. 1996. An integrated approach to biotechnology development. In: Bunders, J., Haverkort, B. and Hiemstra, W. (eds). Biotechnology: Building on Farmers' Knowledge. Macmillan, London and Basingstoke. pp. 201-227.

Ceccarelli, S. 1989. Wide adaptation: how wide? Euphytica 40: 197-205.

Ceccarelli, S. 1997. Adaptation to low/high input cultivation. In: P.M.A. Tigerstedt (eds.). Adaptation in Plant Breeding. Kluwer Academic Publishers, The Netherlands. pp. 225-236.

Ceccarelli, S. 1994. Specific adaptation and breeding for marginal conditions. Euphytica 77 (3):205219.

Ceccarelli, S. and Grando, S. 1996. Importance of specific adaptation in breeding for marginal conditions. In: Hailu, G. and Joop Van Leur (eds.). Barley Research in Ethiopia: Past Work and Future Prospects. Proceedings of the $1^{\text {st }}$ Barley Research Review Workshop, 16-19 October 2003, Addis Ababa: IAR/ICARDA. Addis Ababa, Ethiopia. pp. 34-58.

Chahal, G.S. and Gosal, S.S. 2002. Principles and Procedures of Plant Breeding: Biotechnological and Conventional Approaches. Narosa Publishing House, New Delhi.

Cleveland, D.A. 2001. Is plant breeding science objective or social construction? The case of yield stability. Agriculture and human values 18: 251-270.

Coffman, W.R. and Smith, M.E. 1991. Roles of public, industry and international research center programs in developing germplasm for sustainable agriculture. In: Sleper, D.A., Baker, T.C., Bramel-Cox, P.J. and Francis, C.A. (eds.). Plant breeding and sustainable agriculture: consideration for objectives and methods. Proceedings of a Symposium in Las Vegas, CSSA Publication No. 18, Crop Science Society of America, Madison. pp. 1-9.

CSA (Central Statistics Authority). 2005. Agricultural sample survey 2004/2005. Vol. III. Report on farm management practices (private peasant holdings, meher season). Central Statistics Authority. Addis Ababa.
CSA (Central Statistics Authority). 2006. Statistical Abstract 2005. Addis Ababa, Ethiopia

de Boef, W.S., Berg, T. and Haverkort, B. 1996. Crop genetic resources. In: Bunders, J. Haverkort, B. and Hiemstra, W. (eds). Biotechnology: Building on Farmers' Knowledge. Macmillan, London and Basingstoke. pp. 103-128.

EARO (Ethiopian Agricultural Research Organization). 2000. National crop research strategy. EARO, Addis Ababa, Ethiopia.

Edmeades, G.O., Bolanos, J., Banziger, M., Ribaut, J.M. White, J.W., Reynolds, M.P. and Lafitte, H. R. 1998. Improving crop yields under water deficits in the tropics. In: Chopra, V.L., Singh, R.B. and Varma, A. (eds.). Crop Productivity and Sustainability - Shaping the Future. Proceedings of the $2^{\text {nd }}$ International Crop Science Congress. Oxford and IBH, New Delhi. pp. 437-451.

Ethiopian Agricultural Sample Enumeration. 2002. Report on the preliminary results of area, production and yield of temporary crops (meher season, private peasant holdings). Part I. Central Statistics Authority, Addis Ababa, Ethiopia.

Falconer, D.S. 1960. Introduction to Quantitative Genetics. $2^{\text {rd }}$ ed. Longman, London, England.

Falconer, D.S. 1989. Introduction to Quantitative Genetics. $3^{\text {rd }}$ ed. Longman, London, England.

FAO (Food and Agriculture Organization of the United Nations). 1984. Fertilizer and plant nutrition guide. FAO. FAO Fertilizer and Plant Nutrition Bulletin, Rome.

Farrington J. and Martin, A.M. 1988. Farmer participatory research: A review of concepts and recent field works. Agricultural Administration and Extension 29: 247-264.

Franzel, S. 1992. Background and objective. In: Franzel, S. and van Houten, H. (eds.). Research with Farmers: Lessons from Ethiopia. C.A.B International, Redwood Press Ltd., Melksham, UK. pp. 3-8.

Gemechu, K., Belay, A. and Mussa, J. 2001. Efficiency of drained selection environment for improving grain yield in faba bean under undrained target environments on Vertisol. Euphytica 122(2): 279-285.

Gemechu, K., Mussa, J., Belay, A. and Maaza, K. 2002. On-farm evaluation of faba bean and field pea varieties around Holetta. In: Gemechu, K., Yohannes, G., Kiflu, B., Chilot, Y. and Asgelil, D. (eds.). Towards Farmers' Participatory Research: Attempts and Achievements in the Central Highlands of Ethiopia. Proceedings of Client-Oriented Research Evaluation Workshop, 16-18 October 2001, Holetta Agricultural Research Center, Holetta, Ethiopia. pp. 176-187.

Getachew, A. and Amare, G. 2004. Effects of drainage and genotype on yield and some yield components of faba bean on a highland Vertisol 
in Ethiopia. Ethiopian Journal of Natural Resources 6 (2): 167-187.

Getaw, T. and Girma, T. 2004. Farmers' adoption of wheat and barley technologies in the highlands of Welo. In: Sebil. Proceedings of the $10^{\text {th }}$ Annual Conference of the Crop Science Society of Ethiopia. 19-21 June 2001, Addis Ababa, Ethiopia. pp. 234-245.

Graham, R.D. 1988. Development of wheat with enhanced nutrient efficiency: Progress and potential. In: Klatt, A.R. (eds.). Wheat Production Constraints in Tropical Environments. Mexico, D.F. CIMMYT. pp. 305-320.

Hailu, B., Workneh, N. and Shelemew, W. 1994. Small holder practices and constraints in Ethiopia. In: Asfaw, T., Geletu, B., Saxena, M.C. and Solh, M.B. (eds.). Cool-season Food Legumes of Ethiopia. Proceeding of the First National CoolSeason Food Legumes Review Conference, 1620 December 1993, Addis Ababa, Ethiopia. ICARDA/IAR. ICARDA, Syria. pp. 19-30.

Hailu, B., Chilot, Y. and Amare, Y. 1996. Smallholder barley production practices and constraints. In: Hailu, G. and Joop Van Leur (eds.). Barley research in Ethiopia: Past work and future prospects. Proceedings of the $1^{\text {st }}$ Barley Research Review Workshop, 16-19 October 2003, Addis Ababa: IAT/ICARDA. Addis Ababa, Ethiopia. pp. 138-144.

IAR (Institute of Agricultural Research). 1986. Proceedings of the $18^{\text {th }}$ National Crop Improvement Conference (NCIC), 24-26 April 1986, Nazret, IAR, Addis Ababa, Ethiopia.

Kenea, Y. 2004. On farm analysis of improved chickpea production technologies in East Shoa, Ethiopia. In: Sebil. Proceedings of the $10^{\text {th }}$ Annual Conference of the Crop Science Society of Ethiopia. 19-21 June 2001, Addis Ababa, Ethiopia. pp. 216-223.

Legesse, D. 2004. Agricultural research and technology development in Ethiopia. In: Tesfaye, Z., Legesse, D. and Dawit, A. (eds.). Agricultural Technology Evaluation, Adoption and Marketing. Proceedings of the Workshop Held to Discuss the Socio-economic Research Results of 1998-2002, August 6-8, Addis Ababa, Ethiopia. pp. 1-20.

MoARD (Ministry of Agriculture and Rural Development). 2005. Crop Variety Register. Issue No. 8. Addis Ababa, Ethiopia.

Quinones, M.A., Borlaug, N.E. and Dowswell, C.R.1997. A fertilizer-based green revolution for Africa. In: Replenishing Soil Fertility in Africa. SSSA Special Publication No 51. Agronomy and Soil Science Society of America, 677 S. Segoe Rd., Madison, W1 53711, USA. pp 81-95.

Reijntjes, C., Haverkort, B. and Waters-Bayer, A. 1992. Farming for the Future: An Introduction to Low-External-Input and Sustainable Agriculture. Macmillan, London.

Rezene, F. 1994. Weed research in cool-season food legumes. In: Asfaw, T., Geletu, B., Saxena, M.C. and Solh, M.B. (eds.). Cool-Season Food Legumes of Ethiopia. Proceeding of the First National Cool-Season Food Legumes Review Conference, 16-20 December 1993, Addis Ababa, Ethiopia. ICARDA/IAR. ICARDA, Syria. pp. 252-274.

Rosielle, A.A. and Hamblin, J. 1981. Theoretical aspects of selection for yield in stress and non-stress environments. Crop science 21: 943-946.

Simmonds, N.W. 1991. Selection for local adaptation in a plant breeding programme. Theoretical and Applied Genetics 82: 363-367.

Singh, B.D. 2002. Plant Breeding: Principles and Methods. $6^{\text {th }}$ edition. Kalyani Publishers, New Delhi.

Singh, R.B. 2000. Environmental consequences of agricultural development: a case study from the Green Revolution state of Haryana, India. Agricultural Ecosystem and Environment 82: 97103.

Smith, M.E. 1986. Breeding for multiple cropping systems. In: Francis, C.A. (eds.). Multiple Cropping Systems. Macmillan Publishing Company, New York. pp. 219-249.

Tesfaye, K. 1988. Selection for milk production in the indigenous cattle of the tropics. In: Proceedings of the $2^{\text {nd }}$ National Livestock Improvement Conference (NLIC). 24-26 February 1998, Addis Ababa, Ethiopia. pp. 88-91.

Van Oosterom, E.J., Kleijn, D., Ceccarelli, S. and Nachit, M.M. 1993. Genotype by environment interaction of barley in the Mediterranean Region. Crop Science 33: 669-674

Wallace, D.H. and Yan, W. 1998. Plant Breeding and Whole-System Crop Physiology. University Press, Cambridge, UK.

Woldeyesus, S. and Chilot, Y. 2002. Participatory client orientation of research in low-input cropping systems of Ethiopia: A view point. In: Gemechu, K., Yohannes, G., Kiflu, B., Chilot, Y. and Asgelil, D. (eds.). Towards Farmers' Participatory Research: Attempts and Achievements in the Central Highlands of Ethiopia. Proceedings of Client-Oriented Research Evaluation Workshop, 16-18 October 2001, Holetta Agricultural Research Center, Holetta, Ethiopia. pp. 27-43.

Woldeyesus, S., Ralph, G. and Anton, E. 2002. Environment of selection in low fertilizer input barley. Field Crops Research 74: 151-162. 